\title{
A missão Summer Institute of Linguistics e o indigenismo latino-americano: história de uma aliança (décadas de 1930 a 1970)
}

\author{
Maria Cândida Drumond Mendes Barros \\ Pesquisadora do Museu Emílio Goeldi
}

\begin{abstract}
RESUMO: O trabalho aborda a história da aliança entre a missão evangélica Summer Institute of Linguistics e os intelectuais latino-americanos entre as décadas de 1930 e 1970 . A proposta é reconstruir o contexto político e intelectual em que essa aliança ocorreu no México, Peru e Brasil. Em particular, será focalizado o papel do Instituto Indigenista Interamericano como espaço de contato da missão com os governos latino-americanos.
\end{abstract}

PALAVRAS-CHAVE: missão evangélica, Summer Institute of Linguistics, indigenismo, lingüística indígena, Instituto Indigenista Interamericano.

A missão evangélica americana Summer Institute of Linguistics (SIL), criada no México na década de 1930, expandiu-se na América Latina por meio de alianças com intelectuais latino-americanos e não com o apoio das igrejas evangélicas locais (Stoll, 1985). A missão teve como política manter "padrinhos", "protetores" ou "patronos" entre políticos e intelectuais, tais como Lázaro Cardenas no México, Vargas Llosa no Peru e Darcy Ribeiro no Brasil.

Um dos principais aliados da missão foi o indigenismo estatal latino-americano representado pelo Instituto Indigenista Interamericano (III). A proximidade do SIL com esse grupo pode ser verificada pela 
Maria C. D. M. Barros. A missão Summer Institute of Linguistics...

participação dos membros da missão nas reuniões do III como parte das delegações oficiais dos governos latino-americanos, sem ter tido a mesma participação nas delegações americanas (Cowan, 1979, p. 213).

O SIL não foi o único caso de missão evangélica a manter relações de aliança com grupos nacionais não-evangélicos como forma de sustentação política. Um exemplo dessa parceria é a que se deu na Guatemala entre os políticos liberais e os missionários protestantes no período de 1872-1954 (Yannakakis, 1997). Esse expediente era conveniente na ausência de uma Igreja Evangélica local forte que a respaldasse em face do domínio da Igreja Católica. Porém, essas alianças não tiveram maiores influências nessas missões: a identidade dos missionários e o organograma dessas missões não sofreram modificações para atender a esse tipo de aliança com os não-evangélicos.

O peculiar ao SIL foi ter sido projetado para atender à aliança com o movimento indigenista. Essa aliança entre evangélico fundamentalista e os indigenistas anticlericais não trouxe modificações nos objetivos religiosos da missão, que se mantiveram os mesmos; as mudanças ocorridas nesse grupo missionário como conseqüência dessa aliança se efetuaram na sua identidade pública e no tipo de organograma institucional da missão. A aliança acabou gerando a dupla identidade do membro do SIL (a de missionário para o público evangélico e a de lingüista para os grupos nacionais) e a estruturação institucional dupla entre SIL e Wycliffe Bible Translators.

Para Stoll (1985), essa aliança entre o indigenismo estatal de caráter anticlerical e uma missão fundamentalista é a chave para entender a expansão posterior da missão em toda a América Latina e o surgimento da dupla identidade de missionário e lingüista. $\mathrm{O}$ fim dessa aliança se deu a partir da década de 1970, quando a dupla identidade, até então um pacto mútuo entre missionários e intelectuais, entrou em crise e passou a ser vista como uma política de conspiração (Stoll, 1984). 
A proposta do presente trabalho será tratar a história da aliança entre a missão evangélica SIL e os intelectuais latino-americanos por meio da reconstrução do contexto político e intelectual em que esta aliança ocorreu, com ênfase no período inicial no México, onde alguns traços institucionais que caracterizam o SIL - missionário oculto pela identidade científica, relação próxima com os órgãos do governo e participação nos projetos de escola pública indígena - foram estabelecidos e se cristalizaram como norma e estratégia da missão para o resto da América Latina. O Peru e o Brasil são exemplos de países onde teve eco a experiência da missão iniciada no México.

\section{A missão Summer Institute of Linguistics}

O SIL é uma missão evangélica especialista na tradução do Novo Testamento para línguas ágrafas. A tradução configura um padrão de evangelização próprio para comunidades rurais pequenas, falantes de línguas ágrafas e que conservam o predomínio da comunicação "face a face":

the translation strategy is an approach to missionary work in which the only formal missionary activity is translating the Bible (or parts of it) into the mother tongue of those being evangelized and teaching them to read it with understanding. (Dye, 1979, p. 14)

Essa estratégia significou iniciar a evangelização pela tradução, diferentemente de outras missões onde essa atividade só ocorria quando já houvesse na comunidade uma igreja estruturada, com pastores e crentes. Essa era, por exemplo, a regra da American Bible Society em 1932 (Nida, 1947), que supunha a formação de um comitê de crentes da comunidade para acompanhar a tradução. No caso do SIL, a iniciativa da 
Maria C. D. M. Barros. A missão Summer Institute of Linguistics...

tradução é de um não-falante nativo, o missionário, que dirige o processo de tradução por meio da assistência de informantes da língua.

Uma característica do SIL é o caráter não eclesiástico da evangelização pela tradução. O missionário não oficializa nenhum culto ostensivamente, porém, através do permanente diálogo com o informante nativo durante a tradução, estabelece uma modalidade de curso bíblico (Dye, 1979, p. 17). A tradução bíblica se torna uma forma de conversão de um pequeno grupo, que deverá vir a ter funçóes de agentes evangélicos na comunidade. Os informantes da língua se transformam em membros em potencial de uma igreja evangélica na comunidade, razão pela qual é fundamental que o missionário estabeleça um vínculo forte com o seu grupo de auxiliares.

Translation helpers are therefore the key individuals who will pass on what they know to others. They are the spiritual "Timothys" on whom translators rely to evangelize and teach others what the translator has been quietly teaching them. (Dye, 1979, p. 17)

Em termos religiosos, o SIL funciona como uma missão de fé, ou seja, não tem ligações com nenhuma igreja evangélica em particular. Sua composição é formada por membros de diferentes denominações evangélicas originárias do fundamentalismo americano, que compartilham uma interpretação literalista do texto bíblico (Fernandes, 1980).

Em termos institucionais, o SIL faz parte de um conglomerado missionário, que inclui a Jungle Aviation and Radio Service (JAARS) e a Wycliffe Bible Translators (WBT). Cada uma dessas instituições tem funções diferentes. A JAARS dá suporte tecnológico para o membro do SIL no campo, com aviōes, rádios e computadores. A WBT tem uma definição religiosa: é a encarregada da divulgação do trabalho de conversão entre o público evangélico, do recrutamento de membros e da 
Revista de Antropologia, São Paulo, USP, 2004, v. 47 no 1.

obtenção de fundos para a JAARS e o SIL. Todo membro do SIL ou da JAARS é necessariamente membro da WBT, é ali que devem prestar a cada seis anos juramento sobre os "Princípios de Doutrina", que incluem a afirmação da verdade absoluta da Bíblia, da salvação eterna para o crente e da punição para o não-crente (Stoll, 1985, p. 23).

Apesar de a WBT possuir a identidade religiosa, o trabalho de conversão nos grupos étnicos é tarefa do SIL. Todo trabalho da JAARS ou da WBT se dirige para apoiar o membro do SIL no trabalho de conversão. Contudo, nos países onde atua, o SIL não é conhecido pelo seu trabalho de evangelização, mas sim pelos seus trabalhos em lingüística sobre línguas ágrafas e pelos projetos de educação bilíngüe. Em vários países da América Latina, eles atuam na área da educação indígena oficial.

Ser membro do SIL (lingüista) ou da WBT (missionário) depende do público a quem se dirige: "casa" (home) ou "campo" (field) (Cowan, 1979). Home é o público evangélico americano que apóia com orações e dinheiro a missão. Para esse público, quem se apresenta é o membro da WBT, cujo principal interesse é a conversão da população indígena. O perfil que se apresenta é o do missionário pioneiro atuando em áreas remotas, nas fronteiras com o mundo não-evangélico (Steven \& Hefley, 1972, p. 12).

O "campo" (field) se refere aos governos e às academias dos países onde a missão atua. Para esse público, os membros do SIL se apresentam como lingüistas ou educadores, no máximo missionários técnicos, membros de uma missão não-devocional, com uma atuação essencialmente laica. Para o pessoal do "campo", o missionário está oculto; o que se vê é a identidade de lingüista trabalhando com informantes nativos.

Esse jogo de identidades do membro do SIL entre o cientista e o religioso foi trabalhado por David Stoll $(1981 ; 1985)$, que aponta a conjuntura política na América Latina como causa de sua origem e traça o percurso das várias formas pelas quais a relação entre o SIL e a WBT foi 
Maria C. D. M. Barros. A missão Summer Institute of Linguistics...

apresentada na América Latina. A identidade de lingüista surge como parte da estratégia do "missionário oculto", que significou apresentar o SIL como integrante da Universidade Oklahoma (onde o SIL manteve os seus cursos de verão de lingüística para candidatos à missão), enquanto deixava encobertos os vínculos (permanentes) com a WBT.

\section{A política de aliança do SIL na América Latina (décadas de 1930 a 1970)}

O estrategista da política de aliança com o público não-evangélico por parte da missão foi William Cameroun Townsend, seu fundador e diretor por três décadas. Quando criou o SIL em 1936, Townsend vinha de uma experiência de 14 anos como missionário na América Central (1917-1931), primeiro como pregador e vendedor itinerante da Bíblia em espanhol, depois como missionário-tradutor entre os Cachiquel (Guatemala) pela Central American Mission (CAM). Desligou-se da CAM e fundou em 1934 o Camp Wycliffe, um curso de treinamento de missionários em uma fazenda de Arkansas (EUA), dirigido para atuar na tradução da Biblia.

O México foi pensado como o país onde seus alunos se iniciariam na vida de missionários. Para esse fim, Townsend esteve no México, primeiro em 1933, período da campanha eleitoral de Lázaro Cardenas para presidência, a fim de sondar as possibilidades de entrar com seu grupo no país, e depois em 1935, já com Cardenas no poder. Em sua primeira estada, Townsend teve problemas para entrar e se estabelecer, mas, na segunda vez, como fruto dos seus contatos no México, teve permissão para atuar em uma comunidade nahuatl.

Quanto ao principal aliado de Townsend na América Latina, o movimento indigenista, este se apresentou com diferentes bases teóricas em 
cada país: no Peru, o marxismo foi o suporte teórico das posições de José Mariategui; no Brasil, o positivismo foi o embasamento do seu principal mentor, Cândido Rondon; mas, no México, o indigenismo se sustentava na antropologia. Alguns dos seus principais autores foram os antropólogos Manuel Gamio e Moises Sáenz. Posteriormente, tanto no Peru como no Brasil, o indigenismo passou a ter também a antropologia como seu embasamento teórico.

Uma das bandeiras de luta do movimento indigenista na América Latina foi a de que o Estado substituísse as missões religiosas, como agente de intermediação com as populações indígenas, por meio do estabelecimento de burocracias próprias. Essa posição significou a crítica ao instrumento das concordatas, que representavam acordos entre Estados nacionais e a Igreja Católica para esta última atuar nas áreas indígenas. Considerava-se que a figura legal da concordata era anacrônica em um Estado nacional laico. A crítica às missões era dirigida à Igreja Católica e ao seu modelo de educação indígena representado pelos internatos.

\subsection{O contexto político-intelectual do México na criação da missão}

Os governos posteriores à Revolução Mexicana se caracterizaram por uma política anticlerical direcionada à Igreja Católica. Entre as medidas anticlericais, estavam a obrigação de os padres pagarem uma taxa especial ao Estado, o fechamento das escolas religiosas e a expropriação dos bens da Igreja Católica. Nesse contexto anticlerical, a figura do missionário não era reconhecida legalmente, mas foi exatamente nessa conjuntura que o SIL foi criado em 1936, durante o governo de Lázaro Cardenas (1934-1940). 
Maria C. D. M. Barros. A missão Summer Institute of Linguistics...

Algumas conjunturas do governo de Cardenas acabaram por reverter em favor da criação de uma missão no país, apesar das dificuldades legais para os grupos religiosos atuarem ali. Entre os fatores favoráveis estavam:

- O início do programa de "Educação Socialista" e a discussão sobre a escola pública indígena:

Após o período armado da Revolução Mexicana, a educação pública no México ganhou importância como sustentação e consolidação dos governos. As escolas propagandeariam os ideais da revolução em oposição à Igreja Católica, a principal instituição educadora do país e um dos principais adversários do movimento revolucionário.

O clímax da luta política contra a Igreja Católica no campo educacional ocorreu no governo de Lázaro Cardenas, quando se estabeleceu o programa de "Educação Socialista", que significou a montagem de uma rede de escolas públicas que substituiriam aquelas promovidas pelas paróquias. De acordo com esse projeto, as escolas privadas deveriam seguir os mesmos programas e livros das oficiais, obrigatoriamente numa linha científica positivista, estando proibida a educação religiosa.

- A oficialização do movimento indigenista e da proposta de uma educação indígena diferenciada:

$\mathrm{O}$ indigenismo como política pública representava a defesa de que a administração das áreas indígenas deveria ser responsabilidade dos antropólogos, considerados um misto de cientista e burocrata. Sua reivindicação era que os programas governamentais nas áreas indígenas deveriam ser diferenciados daqueles dirigidos para as áreas rurais do país.

Durante o governo de Cardenas, foi criado o Departamento de Assuntos Indígenas, a partir de uma proposta do antropólogo Moises Sáenz, que havia pensado chamá-lo de "Departamento de Nacionalización del Indio" (Sáenz, 1936, p. 346). O órgão deveria levar à frente 
Revista de Antropologia, São Paulo, USP, 2004, v. 47 no 1.

um programa de "mexicanização" do índio, fazendo uso instrumental da antropologia para alcançar seus fins. Nessa perspectiva, o programa de "Educação Socialista" a ser levado para as comunidades indígenas deveria ser gerido pelos indigenistas. A escola indígena seria o instrumento de incorporación do índio ao Estado nacional, porém por meios diferenciados daqueles usados nas escolas rurais.

- O papel central da antropologia no cenário acadêmico do México:

A proposta indigenista foi ganhando espaço nos governos pela influência cada vez maior da antropologia no meio intelectual mexicano. Essa disciplina foi oficializada em 1937 como curso superior com a criação da Escuela Nacional de Antropología e Historia. Não apenas o intelectual mexicano se interessou pela antropologia, como também os antropólogos estrangeiros se interessaram pelo país. Malinowski, Jules Henry e Robert Redfield, entre outros, estiveram no México como professores ou pesquisadores. A difusão da antropologia ocorreu paralelamente à de suas subdisciplinas - lingüística e arqueologia.

A influência da antropologia no indigenismo mexicano teve como conseqüência a crítica da visão do índio como diferença racial. Essa concepção foi substituída pela definição do índio por meio dos conceitos de cultura e de língua. Nos anos 30, o conceito de língua indígena se tornou a forma de identificar a população indígena no censo nacional de 1930, que incluiu critérios lingüísticos para contabilizá-la (quantos eram monolíngües em língua indígena, quantos eram bilíngües etc.) (Asamblea de Filologos y Linguistas, 1940, p. 34). Trocava-se o conceito de raça pelo de língua no discurso dos indigenistas: "La diferencia fundamental que existe entre la raza indigena y el resto de la población mexicana es sin duda el idioma" (Basauri, 1937, p. 57).

O desenvolvimento da antropologia no México se caracterizou por sua definição como ciência aplicada ("ciência normativa”) à adminis- 
Maria C. D. M. Barros. A missão Summer Institute of Linguistics...

tração pública, como defendia Gamio (1960, p. 15) em 1916. Essa concepção de ciência aplicada foi estendida também às subdisciplinas da antropologia; elas deveriam ser o guia para a ação do governo nas áreas indígenas, em especial nos programas de educação oficial. Nestes últimos, a lingüística deveria ter um papel central: "El lingüista está listo ahora para ayudar el gobierno a resolver los problemas de la educación indigena, sin abandonar el campo científico" (Asamblea de filologos y linguistas, 1940, p. xv).

Um exemplo do interesse do movimento indigenista pela lingüística, e sua definição como ciência auxiliar na área da educação indígena, pode ser encontrado na criação do Instituto Mexicano de Investigaciones Linguísticas (IMIL), em 1933, por Mariano Silva y Aceves, ex-reitor da UNAM, considerado um intelectual de esquerda (Instituto Mexicano de Investigaciones Linguisticas, 1937, n. 3/4, p. v). O editorial do primeiro número do periódico Investigaciones Linguísticas do IMIL continha as tradicionais bandeiras políticas do indigenismo, como a defesa da educação diferenciada para o indígena (idem, 1933, n. 1, p. 9). O IMIL relacionava lingüística a pedagogia, da mesma maneira que o indigenismo havia feito com a antropologia.

O IMIL apontava para o vazio de "cultura lingüística" que havia no país e propunha suprir esta falta por meio de um programa de ação que incluía publicaçôes e formação de academias de estudiosos de línguas indígenas (idem, 1933, n. 1, p. 7; n. 2, p. 63). Entre 1933 e 1938, a instituição publicou o periódico Investigaciones Linguísticas, com interrupção em 1936.

- As ameaças de invasão americana devido à nacionalização do petróleo:

Outro acontecimento importante durante o governo de Cardenas, com reflexos na forma de atuação de Townsend, foram a nacionalização do petróleo e as intensas disputas entre os dois governos quanto ao va- 
lor da indenização. Nesse período houve muita tensão diante das ameaças de invasão americana ao país, em defesa das companhias petroleiras desapropriadas, tornando valioso, em termos de propaganda, o apoio de um religioso americano ao governo mexicano.

Foi nesse contexto político e intelectual que Townsend decidiu em 1936 transformar o que era apenas um curso de treinamento de missionários - o Camp Wycliffe - em uma missão - o Summer Institute of Linguistics. Townsend tirou proveito dessa conjuntura para criar uma missão evangélica com atuação na área da educação pública indígena com apoio oficial e acadêmico.

\subsection{A formação da dupla identidade}

Apesar da legislação anticlerical vigente, o governo de Cardenas representou um período favorável à entrada no país de grupos protestantes que não exercessem atividades eclesiásticas publicamente, estando assim conformes às leis. É dessa época a entrada da Associação Cristã de Moços (Townsend, 1952) e do Exército da Salvação (Daniels, 1947). A partir dessa limitação legal à atividade religiosa no México, Townsend estabeleceu como regra para a missão uma linha de atuação não-eclesiástica, que favoreceria o perfil de missionário centrado em questōes de tradução.

Por ser o missionário uma figura não reconhecida legalmente no país, a identidade pública de lingüista por parte do grupo de Townsend se tornou conveniente para conseguir permissão para entrar nas áreas indígenas. O clima intelectual no México em torno da lingüística e das línguas indígenas era propício para se entrar no país como lingüista e não como missionário, além de ser uma identidade adequada à função de tradutor bíblico. 
Maria C. D. M. Barros. A missão Summer Institute of Linguistics...

We will enter México as linguists rather than as missionaries. (...) The Indian languages must be learned and the New Testament translated into them. It matters not to us whether we be classified as missionaries or ditchdiggers if we be given a chance to labor toward that end. (Townsend in Hefley \& Hefley, 1974, p. 82)

Devido à importância que o indigenismo mexicano havia dado à lingüística como uma disciplina necessária para a prática do Estado na área de educação indígena, a identidade de lingüistas foi profícua politicamente para fundar ali, em 1936, uma missão. O nome escolhido para a missão procurou ressaltar a identidade acadêmica em detrimento da identidade religiosa: Instituto de Lingüística era tanto o nome do curso de verão, organizado anualmente pela Linguistic Society of America, como também o nome da instituição criada em 1933 por Mariano Silva y Aceves, o Instituto Mexicano de Investigaciones Linguísticas.

A experiência do IMIL foi determinante para a escolha da identidade de lingüista por parte do grupo missionário. Não bastava apenas se auto-identificar como lingüista, era fundamental fazê-lo no espaço legitimado no México para a lingüística indígena, que era o IMIL. O SIL começou a marcar presença nas publicações do IMIL por meio de artigos, notas e anúncios. As referências ao SIL, por parte dos mexicanos, eram sempre dirigidas ao caráter científico do interesse daquele grupo pelas línguas indígenas: "Como se ve, el trabajo de estos investigadores extrangeros [do SIL] ha venido a animar grandemente los estudios linguisticos en nuestro país" (Instituto Mexicano de Investigaciones Linguisticas, 1937, n. 1/2, p. 5). Não havia nenhuma referência à identidade religiosa do grupo.

A parceria entre o SIL e o IMIL estava fundamentada em alguns pontos em comum em termos de política indigenista. Ambos compartilhavam da concepção de que a integração dos índios (ao Estado ou à Igre- 
ja) ocorreria por meio da educação e de que o professor indígena era o agente privilegiado da mudança cultural almejada. As duas instituições concebiam as línguas indígenas como possíveis de serem "incorporadas", através de seu uso como meio de proselitismo. A diferença estava em relação a que textos pretendiam traduzir: discursos políticos e leis do governo ou o Novo Testamento.

Se o IMIL foi fundamental para a identidade de lingüista por parte do missionário, também o SIL foi peça fundamental para indigenistas e lingüistas reunidos no IMIL. A missão, por exemplo, teve importância no retorno da publicação do IMIL, depois de um ano interrompida. Grande parte dos trabalhos apresentados na Semana Lingüística do IMIL em 1936 foi do SIL.

\subsection{O compadrio político como forma de expansão da missão}

Para garantir a permanência legal e a sustentação do seu grupo no país, Townsend montou uma rede de relações com pessoas do governo e intelectuais. O projeto de Townsend de atuar no México com seu grupo surgia já direcionado a manter uma articulação com o governo, se for observado o programa do primeiro Camp Wycliffe de 1934, que incluía, entre os cursos, um voltado para os projetos governamentais para a área indígena ("Governmental Programs regarding the Indians"), matéria dada pelo próprio Townsend (Wallis \& Bennett, 1959, p. 46).

Em 1933, quando Townsend chegou ao México pela primeira vez, ele procurou estabelecer contatos com o governo por meio do historiador americano e socialista Franz Tannenbaum, da Universidade de Columbia, que tinha um bom trânsito entre os mexicanos em virtude do seu livro simpático à Revolução Mexicana (Peace by Revolution). Contam os biógrafos de Townsend que este comprou o livro de 
Maria C. D. M. Barros. A missão Summer Institute of Linguistics...

Tannembaum e lhe pediu um autógrafo (Hefley \& Hefley, 1974, p. 72). Com uma carta de referência do autor e o livro autografado, ele procurou Rafael Ramirez, o responsável pela educação na área indígena.

Townsend não teve permissão de Ramirez para trabalhar em educação nas comunidades indígenas, como era seu desejo, mas lhe foi permitido permanecer no país por seis semanas para visitar as escolas rurais mexicanas. Posteriormente, um bom relacionamento com Ramirez foi conseguido quando o missionário escreveu um artigo elogioso sobre a educação rural mexicana, publicado no Dallas News e no School and Society (Hefley \& Hefley, 1974, p. 82), e enviou cópias para o responsável pela educação indígena. Este passou a incluir Townsend no rol dos amigos da Revolução Mexicana.

Devido aos bons contatos com Ramirez, o retorno de Townsend ao México em 1935, acompanhado do seu primeiro grupo de alunos do Camp Wycliffe, teve melhores resultados do que em 1933. Townsend conseguiu permissão para trabalhar numa comunidade nahuatl em Tetelcingo. Sua atuação naquela comunidade mostrou-se conveniente ao indigenismo estatal. Para os indigenistas, Townsend funcionava em Tetelcingo como um membro das missōes culturais organizadas pelo governo, ao participar dos projetos de reflorestamento, irrigação, escola e projetos agrícolas.

Durante o tempo em Tetelcingo, Townsend não deixou de cultivar suas novas amizades no governo. Fazia constantes viagens à capital, onde visitava seus conhecidos. A atenção às autoridades foi tão fundamental para Townsend, que mais tarde, com o crescimento do seu grupo, ele se mudou para a Cidade do México, para se ocupar apenas das relações com o governo mexicano e da administração da missão.

Na rede de relações pessoais estabelecida por Townsend no México, seu principal aliado foi o presidente Cardenas, amizade que foi fundamental para a criação e o crescimento da missão no país. Cardenas e 
Revista de Antropologia, São Paulo, USP, 2004, v. 47 no 1.

Townsend se referiam um ao outro como amigos íntimos (Cardenas, 1973, p. 201; Townsend, 1952). Cardenas chama o americano de seu "afilhado", e Townsend lhe chama de "padrinho", relação que estabeleceram a partir do segundo casamento do missionário, realizado na casa de Cardenas em Michoacan. A relação entre ambos expressava uma coincidência de táticas no uso da amizade na política. Townsend tomava a relação de amizade como o mais alto valor para o mexicano:

Mexico is a land of friendship. Friendship is the most valuable medium of exchange. (...) Lázaro Cardenas is a devout worshipper at the altar of friendship. (Townsend, 1952, p. 139)

A aproximação do missionário ao presidente se deu por meio de um relatório favorável à educação mexicana, enviado por Townsend para seus amigos no governo, que o levaram até Cardenas. Naquele momento, o presidente enfrentava a oposição da Igreja Católica, através de uma campanha na imprensa americana, contra a política da educação socialista. Esse documento foi o propulsor da primeira visita de Cardenas a Townsend em Tetelcingo (idem, 1952).

Se Cardenas era uma amizade de conveniência política para Townsend, o mesmo ocorria da parte de Cardenas em relação ao missionário. Townsend representava o apoio de um americano religioso no momento em que a Igreja Católica capitalizava uma campanha contra o governo mexicano nos Estados Unidos. As visitas de Cardenas a Townsend em Tetelcingo se deram durante momentos tensos para a política mexicana. Em 1936, com a questão da educação socialista, e em 1938, poucos meses antes da nacionalização do petróleo.

Como forma de aproximação e de fortalecer contatos com o governo mexicano, Townsend usou muitas vezes o procedimento de publicar artigos ou livros simpáticos às questóes políticas do governo. Um exemplo 
Maria C. D. M. Barros. A missão Summer Institute of Linguistics...

é o panfleto “Truth about Mexico's oil”, publicado em 1940 com uma justificativa da nacionalização do petróleo. Em 1952, escreveu uma biografia sobre Cardenas dirigida ao público americano, para combater a idéia do biografado como comunista e violento e para apresentá-lo como pacifista, anticomunista e democrata.

Em suma, a relação de Townsend com um governo anticlerical, em um momento de conflito com os Estados Unidos, foi frutífera. Por meio dessa aliança, foi possível criar em 1936 uma missão com diretoria e base no México, sob a proteção do governo mexicano. Quando Townsend decidiu transformar o que era apenas um curso de treinamento de missionários tradutores (Camp Wycliffe) no Summer Institute of Linguistics, por problemas com seus financiadores evangélicos, ele recebeu de Cardenas respaldo financeiro e legal para fundar a missão. O presidente o autorizou a trazer tantos missionários quantos quisesse e ainda lhes propiciaria salários como professor rural e preços especiais nos trens. Em 1939, faltando poucos meses para o término do governo de Cardenas, a proposta da missão era crescer o máximo no México porque não se sabia o que aconteceria no próximo governo.

Another urgent call to prayer is that workers be sent to the remaining tribes of Mexico as quickly as possible. President Cardenas' term of office expires in fifteen months, and we do not know what the attitude of his successor will be. We should give ourselves to the special task of occupying the remaining tribes in the next fifteen months, if our Lord tarries. (Legters, 1939)

A possibilidade dessa aliança se devia aos pontos em comum que tinham em relação ao projeto indigenista de incorporação do índio à vida nacional. Missionários e indigenistas não apenas compartilhavam planos mas também vocabulário. Os indigenistas anticlericais falam da "redención do indio" (Gamio, 1960, p. 21; Swadesh, 1940, p. 290) e 
Revista de Antropologia, São Paulo, USP, 2004, v. 47 no 1.

"salvar al Indio" (Instituto Mexicano de Investigaciones Linguisticas, 1937, n. 3/4, p. 188), além de criarem "missões culturais", que vão existir ao longo de todo o período pós-revolução. Esse conteúdo missionário da ação indigenista estava presente no livro do antropólogo Moises Sáenz sobre o projeto de integração indígena que ele dirigia em Carapan: "Eramos misiones de una nueva secta" (Sáenz, 1936, p. ix).

A versão de Townsend da aliança com o público não-evangélico no México pode ser encontrada em sua obra de ficção Tolo, the volcano's son. A tale of Indians and Upheavel in Central America, escrita para o público evangélico. $\mathrm{O}$ romance, escrito durante os primeiros anos de Tonwsend naquele país (Stoll, 1985), reflete seu diálogo com o indigenismo mexicano. Townsend expressa suas idéias indigenistas no romance por meio dos personagens que ali estão caracterizados e apresenta sua aliança como uma forma de conversão dos comunistas aos objetivos evangélicos.

$\mathrm{O}$ enredo de Tolo, the volcano's son. A tale of Indians and Upheavel in Central America refere-se a uma rebelião comunista frustrada na Guatemala, graças à participação de um índio crente. Esse tema está presente no romance em torno de dois personagens: Bartolome ou Tolo, um Cachiquel crente, e Marco, um Quiche socialista. Tolo é um ajudante de tradução de missionários protestantes americanos e professor. Marcos, amigo de infância de Tolo, foi educado nas escolas normais rurais mexicanas, onde acabou se tornando um comunista.

Tolo e Marcos aparecem com diferentes projetos de libertação dos índios, mas compartilham muitos pontos. Ambos sofrem pela situação de servidão dos índios, orgulham-se de serem indígenas e acreditam que o índio deva ser integrado por meio da educação, que se deva abolir o uso do álcool e que se aprenda o espanhol. A discordância entre eles ocorre em relação à maneira de solucionar os problemas da população indígena. Marcos via como solução a organização de uma revolta que 
Maria C. D. M. Barros. A missão Summer Institute of Linguistics...

tomasse a terra dos fazendeiros e as entregasse aos índios. Para Tolo, antes da terra, os índios deveriam perder seus vícios, tais como o álcool e as bruxarias. Para o catequista, a solução viria pela difusão da Bíblia (Townsend, 1936, p. 352). Os dois índios vão trabalhar pelos seus diferentes ideais. Marcos trabalha como caixeiro-viajante, uma forma de propagar suas idéias pelos povoados, enquanto Bartolome participa da tradução da Bíblia, da conversão de outros índios e de projetos de educação.

O desenlace desses diferentes projetos se dá em janeiro de 1932, quando Marcos chama Bartolome para participar de uma reunião com outros índios comunistas liderados por um russo. O plano era tomar terras no país. Marcos pede que Tolo vá à reunião para convencer os demais a não destruírem as igrejas durante o levante. Este comparece na reunião, onde faz um discurso em Cachiquel, que o russo não podia entender. Tolo dissuade os índios de levarem adiante a rebelião, mostrando que o Novo Testamento é a única forma de libertação indígena (idem, p. 437).

O livro encerra com o assassinato de Bartolome pelo russo, que foge para o México com alguns dos seus seguidores, e a conversão de Marcos. Bartolome, com o sacrifício de sua vida, havia conseguido evitar um levante comunista na Guatemala. O Novo Testamento havia sido sua arma de libertação dos índios.

A data da rebelião no romance - janeiro de 1932 - se refere ao movimento político chefiado por Farabundo Marti em El Salvador, com participação dos índios Pipil, de quem Townsend tinha sido supervisor para a Central American Mission (Stoll, 1985). A Guatemala está presente no romance de Townsend como local dos acontecimentos do enredo, retratando algumas das experiências de seu autor no país. Porém, o país presente nas entrelinhas, é o México: o diálogo entre Tolo e Marcos corresponde às experiências do missionário com o indigenismo mexicano. 


\subsection{Projeto Tarasco (1939-1940): aliança em torno da montagem da escola pública indígena}

Moses' mother was given a salary for nursing her own baby - the thing she wanted most to do. In the last months we have seen a parallel to the latter incident here among the Tarascan Indians. As you know, our task is to translate the Scriptures into Tarascan, and give them to these people in their own language. But Tarascan is an unwritten tongue and we foresaw the immense task of teaching thousands of illiterate people to read before the translated Scriptures could reach them. But the Lord saw the task too and a miracle has occurred. The Mexican government, until recently opposed to using anything but Spanish in its educational program, is now undertaking to teach the Indians to read and write their own languages. Their program includes all the Indian dialects of the Republic and they have begun with Tarascan! So I am being paid a small salary to do what we planned to do in the Lord's work anyway, and with the help of some of the world's best authorities on Indian languages. (Lathrop, 1940, p. 11)

Um exemplo da aliança entre missionários do SIL e indigenistas mexicanos no campo da educação foi o Projeto Tarasco (1939-1940), que contou ainda com a participação de dois representantes do Linguistic Society of America, Morris Swadesh e Normam McQuown. Na passagem acima, Max Lathrop, missionário do SIL entre os Purepecha (falantes da língua tarasco), relata para o público evangélico a sua participação nesse programa-piloto de educação indígena, formulado durante o governo de Cardenas, que se caracterizava por iniciar a escolarização por meio de campanhas de alfabetização na língua indígena. Esse programa representava a inserção da escrita necessária ao tradutor bíblico na escola pública. 
Maria C. D. M. Barros. A missão Summer Institute of Linguistics...

O Projeto Tarasco foi o resultado de vários fóruns organizados pelos indigenistas durante o governo Cardenas, nos quais se defendeu a especificidade da escola indígena, a entrada da língua indígena na educação e o papel central da lingüística na sua condução. A proposta era que a escola indígena fosse iniciada pela introdução da escrita em língua indígena. O espanhol entraria apenas no segundo e terceiro anos da escola, depois da alfabetização na língua indígena.

Uma característica desse programa-piloto era ser lingüístico em todas as suas fases: cabia exclusivamente ao lingüista fazer os primeiros estudos, estabelecer um alfabeto e dirigir as missões culturais alfabetizadoras. Foi o primeiro programa de educação pública na América Latina que oficializava a alfabetização pela língua indígena fazendo uso de argumentações da lingüística.

O grupo indígena escolhido como balão de ensaio das propostas indigenistas foi o Purepecha, no Estado de Michoacan, terra natal de Cardenas. O Projeto Tarasco, apesar de estar voltado para um grupo indígena em particular, fora formulado pelos indigenistas como um modelo de educação indígena a ser aplicado em todo o México (Swadesh, 1939, p. 223) e até mesmo em toda a América Latina (McQuown, 1939, p. 222) por meio da sua apresentação e aprovação na primeira reunião do Instituto Indigenista Interamericano em 1940.

O Projeto Tarasco era corolário de um extenso debate entre os intelectuais mexicanos sobre como deveria ser a escola pública indígena, debate este que se estendeu ao longo do período da pós-revolução. A discussão estava polarizada entre dois grupos: os que defendiam que a educação indígena deveria ser a mesma ministrada à população camponesa, devendo, portanto, estar sob a responsabilidade da Divisão da Educação Rural, e o grupo dos indigenistas que propunha a criação de uma educação indígena diferenciada daquela rural, devendo ser administrada por uma burocracia especial, a dos indigenistas com formação em 
Revista de Antropologia, São Paulo, USP, 2004, v. 47 no 1.

antropologia. Num ponto, os dois grupos concordavam: o objetivo de uma escola indígena era ser o instrumento de incorporación do índio ao Estado nacional. A divergência ocorria em torno de qual método era o mais adequado para alcançar esse fim.

Para os indigenistas, a língua indígena deveria ser usada na escola como o método mais rápido para ministrar conhecimentos científicos e informações sobre o governo. Essa posição havia sido defendida pelo IMIL e foi adotada pelos indigenistas durante o mandato de Cardenas. Um fórum importante sobre a discussão de um projeto indigenista de educação na língua indígena, durante o governo de Cardenas, foi a Primeira Assembléia de Filólogos e Lingüistas, organizada em maio de 1939 pelo Departamento de Antropologia do Instituto Politécnico e pelo recém-criado Departamento de Assuntos Indígenas, órgão que passava a ter o papel de direção da educação indígena no país.

Tanto o Projeto Tarasco como a Primeira Asambléa de 1939 foram o resultado de uma aliança de três grupos: o lingüista americanista, o indigenista mexicano e o missionário evangélico. Os indigenistas estavam presentes tanto no recém-criado Departamento de Antropologia do Instituto Politécnico como no Departamento de Assuntos Indígenas, os dois órgãos que convocaram a reunião de 1939. Os dois eventos tiveram também a participação de ex-membros (Alfredo Barrera Vasquez e Wigberto Jiménez Moreno) do já extinto Instituto Mexicano de Investigaciones Linguísticas.

O Projeto Tarasco e a Assembléia incluíam membros da Linguistic Society of America (LSA), como Morris Swadesh e Norman McQuown. Swadesh foi a estrela de ambos. Pertenciam a ele os vários cargos de direção: diretor da Oficina de Lingüística do Departamento de Assuntos Indígenas, diretor do Projeto Tarasco e do Consejo de Lenguas Indígenas, entre outros. O SIL, apresentado como de "Siloan Springs, Arkansas" (Asamblea de Filologos y Linguistas, 1940, p. 91), esteve presente 
Maria C. D. M. Barros. A missão Summer Institute of Linguistics...

na lista de instituições participantes da Assembléia, e vários dos seus membros assinaram a ata da reunião.

Imerso na aliança dos diferentes grupos em torno do Projeto Tarasco, houve uma disputa de autoridade entre os representantes da LSA e o grupo do SIL a respeito de como deveria ser o alfabeto geral para as línguas indígenas. As divergências entre os dois se dava em relação aos estilos de alfabetos propostos para as línguas indígenas. Quanto a essa divergência, Townsend viu preteridas as sugestóes do seu grupo à dos dois lingüistas norte-americanos com doutorado.

It became apparent that the opinions of those with Ph.D. degrees carried more weight with the Mexican officials than that of the SILers who have analyzed some of the languages and had lived in the villages with the people who spoke those languages, but had no degree. (Pike, 1981, p. 105-6)

Ainda que Townsend apresentasse seu grupo como parte da Escola de Boas e Sapir e houvesse investido para que os missionários fossem reconhecidos como lingüistas, enviando alguns deles para participar do Linguistic Institute do LSA, o grupo ainda era iniciante perto do currículo de Swadesh. Este chegava com mais prestígio acadêmico: título de doutor em lingüística em 1933, sob orientação de Sapir, co-autor de uma monografia com o mestre, representante da Linguistic Society of America e professor universitário. Era um lingüista reconhecido como o discípulo dileto de Sapir.

A disputa pela autoridade nas decisões lingüísticas consolidou na missão a regra de se ter titulação acadêmica. Dessa experiência, Townsend tomou como lição que era fundamental ao missionário desenvolver uma carreira acadêmica. Não era apenas necessário saber lingüística para os cursos internos da missão, mas também como forma de prestígio junto aos governos (idem, p. 106). 


\subsection{Alianças do SIL no Peru e no Brasil: as experiências no México transformadas em normas}

Depois da experiência no México, tornou-se padrão de atuação do SIL nos demais países o de se apresentar publicamente como lingüista e o de procurar atuar na área da educação pública indígena por meio de convênios com os órgãos indigenistas estatais. Exemplos desse modelo de atuação ocorreram na entrada do SIL no Peru e no Brasil. As características da atuação do SIL nesses dois países foram: (a) o papel facilitador do movimento indigenista na entrada da missão; (b) a secularização do programa de escola da missão através da inserção da lingüística; e (c) o uso do instrumento do convênio entre missão e governo como forma atualizada de concordata.

\subsubsection{O papel facilitador do movimento indigenista na entrada da missão}

No governo Cardenas, o indigenismo não foi apenas uma linha de política interna, mas se tornou a marca registrada da sua política diplomática para a América Latina. A explicitação da política diplomática de Cardenas, centrada no indigenismo, ocorreu por meio da criação do Instituto Indigenista Interamericano (III), com sede no México, em 1940, que se propunha incentivar a criação de órgãos indigenistas nos países do continente.

A exportação do indigenismo mexicano pela América Latina através do III levou de carona os missionários do SIL. Os sonhos de Cardenas de uma integração latino-americana pela bandeira do indigenismo foram acoplados aos de Townsend, que sonhava com uma "Americanova", um campo aberto para sua missão (Hefley \& Hefley, 1974). Até a década de 
Maria C. D. M. Barros. A missão Summer Institute of Linguistics...

1970, o III foi o fórum privilegiado para o SIL estabelecer relações com os responsáveis pelo indigenismo na América Latina. Por várias vezes, Townsend e membros do SIL participaram oficialmente dos congressos daquele instituto como parte das delegações. As revistas do III, Boletim Indigenista e América Indígena, foram canais de notícias sobre Townsend e o SIL. São freqüentes artigos assinados por Townsend a respeito do SIL e de seu projeto de educação (Townsend, 1944; 1949). Várias aproximações exitosas do SIL com os governos na América Latina ocorreram durante as reuniōes do III, como aconteceu com o Equador (1952) e a Guatemala (1952). Também para entrar no Brasil, o SIL usou a reunião do III de 1954 como forma de contatar os indigenistas brasileiros (Hefley \& Hefley, 1974; Oliveira, 1981), mas sem êxito, como veremos adiante.

A entrada do SIL no Brasil e no Peru ocorreu no contexto da oficialização do indigenismo de base antropológica, que abria espaço para a figura do lingüista americanista, ou seja, lingüista estudioso das línguas indígenas do continente, na definição da Linguistic Society of America. Essa identidade foi assumida pelos membros do SIL para entrar no Peru e no Brasil.

No Peru, a chegada da missão se deu em 1945, num contexto intelectual favorável ao indigenismo de base antropológica. Naquele ano, a antropologia havia sido oficializada na Universidade de San Marcos e, um ano mais tarde, o Instituto Indigenista Peruano (IIP) foi fundado dentro do modelo mexicano de se criar um órgão de pesquisa em antropologia que colaboraria com o governo na atuação junto aos grupos indígenas. $\mathrm{O}$ antropólogo e os especialistas de suas subdisciplinas (lingüística, antropologia física etc.) foram reconhecidos como mediadores e gestores dos programas governamentais dirigidos às populações indígenas (Instituto Indigenista Peruano, 1949, p. 76). Esse contexto intelectual favorecia a entrada dos missionários-linguistas nos programas oficiais de educação. 
Revista de Antropologia, São Paulo, USP, 2004, v. 47 no 1.

O primeiro contato do SIL com o governo peruano aconteceu em 1943 por meio da identidade de lingüista acadêmico; quem se apresentou foi Kenneth Pike, que havia terminado seu doutorado e estava atuando como professor de tempo parcial na Universidade de Michigan. Pike procurou o Ministério da Educação levando publicações em lingüística, como de costume na aproximação da missão com órgãos do governo. Pike ofertou Phonetics, seu primeiro livro publicado (Hefley \& Hefley, 1974). Os contatos subseqüentes foram feitos por Townsend, que se transferiu do México para o Peru para a montagem da missão naquele país.

Os motivos de uso da identidade de lingüista no Peru foram diferentes daqueles utilizados no México. Enquanto neste, a razão de se apresentar pela identidade científica era o anticlericalismo do Estado, no caso do Peru, a identidade científica evitava conflitos com a Igreja Católica. O catolicismo era a religião oficial e seus missionários detinham o monopólio de atuação junto à população indígena. Nesse contexto, a identidade de lingüista por parte do SIL não atiçava conflitos com a Igreja Católica.

Como no México, os indigenistas peruanos foram os principais aliados dos missionários. Townsend e seu grupo se apresentavam como "indigenistas" (los indigenistas creemos) (Townsend, 1949, p. 39) nos artigos publicados na revista do Instituto Indigenista Peruano. Townsend fortaleceu sua relação no país, por meio de sua participação no IIP, como membro da comissão de antropologia e como parte da delegação peruana nos Congressos Indigenistas Interamericanos. Em 1952 foi criado o Comitê Peruano de Amigos del Instituto Lingüístico de Verano, sob a presidência de Luis Valcárcel, primeiro diretor do Instituto Indigenista Peruano.

No Peru, o indigenismo antropológico que acabou se sedimentando, depois da Segunda Guerra, seguiu a vertente americana e não o viés mexicano, como havia sido a proposta de Cardenas. Grande parte das pesqui- 
Maria C. D. M. Barros. A missão Summer Institute of Linguistics...

sas etnográficas feitas no Peru naquele momento foram desenvolvidas por meio de instituiçóes norte-americanas com apoio do governo americano. Entre as instituições estavam Andean Research Institute, Smithsonian Institution e Viking Fund (Instituto Indigenista Peruano, 1953, n. 9). O SIL entrou no leque dessas instituições através do Servicio Cooperativo Peruano-Norte-Americano (Townsend, 1949, p. 42). A diferença do programa do SIL em relação aos outros projetos de antropologia aplicada é que seria o único a se instalar na Amazônia, enquanto todos os demais estavam voltados quase exclusivamente para a região andina.

No Brasil, a entrada do SIL se deu na década de 1950, quando, no interior do Serviço de Proteção ao Índio (SPI), ocorria uma transição do indigenismo de base positivista (chamada de "fase doutrinária" por Ribeiro) para sua "fase científica" com base na antropologia, ao estilo do indigenismo mexicano: "A orientação do SPI se assenta nos conhecimentos proporcionados pela antropologia” (Ribeiro, 1954, p. 104). Darcy Ribeiro foi o principal representante do indigenismo de base antropológica no SPI e uns dos principais aliados da missão.

\subsubsection{Escola da missão transformada em escola pública}

O Projeto Tarasco, o primeiro no qual o SIL atuou dentro das escolas públicas indígenas na América Latina, durou apenas 14 meses entre os Purepecha, desaparecendo no final do mandato de Cardenas. Porém, o projeto teve vida longa como padrão de educação indígena dentro da linha indigenista, e nesta sobrevida levou junto o SIL. Em pelo menos dois fóruns internacionais, o indigenismo mexicano promoveu o Projeto Tarasco: em 1940, durante o I Congresso Indigenista Interamericano (III), e em 1953, em reunião da UNESCO. Em ambas as reuniōes, o SIL tomou parte como convidado dos indigenistas mexicanos. 
Revista de Antropologia, São Paulo, USP, 2004, v. 47 no 1.

A presença do Projeto Tarasco na UNESCO se deu durante a gestão do mexicano Jaime Torres Bodet como seu diretor. Nesse período, esse projeto tinha sido considerado modelo de educação. Kenneth Pike e Morris Swadesh estiveram nas reuniōes da UNESCO de 1953 como membros da delegação mexicana.

Enquanto a difusão da educação indígena bilíngüe na América Latina se deu nos fóruns indigenistas com influência mexicana, a montagem da escola bilíngüe nesses países ficou por conta exclusivamente do SIL. Depois da experiência no México, tornou-se norma na missão participar de programas oficiais de educação indígena e não se restringir à escola da missão. $\mathrm{O}$ interesse da missão era poder direcionar a educação indígena pública para a alfabetização na língua indígena, imprescindível ao projeto de conversão pela tradução da Bíblia. No Peru, o programa de alfabetização na língua indígena foi oficializado em 1952 com o Programa de Yaricanocha; no Brasil, este processo ocorreu em 1972.

Não havia no Peru a discussão em torno da educação indígena diferenciada da rural, como havia no México. As experiências de escola indígena do governo eram apenas na área andina, realizadas através de granjas educativas, internatos, ou de um projeto conjunto com o governo boliviano para a região do Titicaca. Na Amazônia, as experiências de educação indígena estavam nas mãos das missões católicas organizadas em torno dos internatos. Não se menciona em nenhuma dessas experiências a prática de se usar a língua indígena, oral ou escrita, na escola. A única menção à educação bilíngüe na revista Peru Indígena é uma referência ao próprio Townsend, fazendo uma demonstração do "metodo de lectura y escritura en lenguas aborígenes” entre os Aymara, numa das granjas educacionais do governo (Instituto Indigenista Peruano, 1948, n. 1, p. 28), com o apoio de um programa americano de cooperação.

A revista Peru Indígena se tornou o fórum de Townsend para defender seu projeto de educação. Em vários artigos na revista do Instituto 
Maria C. D. M. Barros. A missão Summer Institute of Linguistics...

Indigenista Peruano, ele defendeu a alfabetização na língua indígena por meio de argumentos integracionistas. Townsend havia assimilado no México os anseios do Estado de integração dos índios e apresentava seu projeto de escola como uma proposta para este fim:

Una vez que puede leer, aunque al principio sea solamente en su propio idioma, se le quita el complejo de inferioridad. Comienza a interesarse en cosas nuevas. Se interesa en comprar artículos manufacturados - implementos, molinos, ropa, etc. (Townsend, 1949, p. 43)

A oficialização do programa do SIL no Peru ocorreu com a criação, em 1952, de um curso de formação de professores indígenas para a região amazônica na base do SIL de Yarinacocha, programa este reconhecido pelo governo peruano como parte daquele de educação oficial (Brend \& Pike, 1977, p. 74). O SIL conseguia estabelecer no Peru o controle da formação do professor indígena, diferentemente do México, onde a missão não tinha tido permissão para atuar nas Escolas Normais Rurais, local de formação dos professores da rede pública. A nãoentrada dos missionários no espaço de formação de professores no México estaria ligada ao papel vital que os professores rurais tiveram como encarregados de consolidar o poder do Estado mexicano no interior do país.

O Programa de Yarinacocha, conforme a versão mexicana do Projeto Tarasco, tinha como figura central o lingüista. Este era o responsável pela elaboração de um alfabeto de base fonológica, pela preparação de cartilhas de alfabetização e pela tradução do material didático na língua do aluno. $\mathrm{O}$ lingüista era quem definia a norma correta da escrita e era quem alfabetizava o futuro professor indígena em sua língua (Larson \& Davis, 1981, p.40). Enquanto no México a principal autoridade lingüística era um membro da Linguistic Society of America (Swadesh), 
Revista de Antropologia, São Paulo, USP, 2004, v. 47 no 1.

no Peru, os missionários se tornaram os únicos lingüistas do projeto e foram coordenadores do Programa de Yarinacocha.

Em relação ao Brasil, a primeira proposta missionária de oficializar o modelo de alfabetização na língua indígena, como programa da escola pública, ocorreu por meio da New Tribes em 1943, tendo como referência o programa de educação desenvolvido no México nos anos 1930 (Freire, 1990, p. 172). A missão propunha enviar mais de cem lingüistas para iniciar os trabalhos, solicitando para isto licença para visitar as áreas indígenas. A reação do Serviço de Proteção ao Índio e de Rondon, então presidente do Conselho Nacional de Proteção ao Índio, foi de recusa por considerar que a educação indígena deveria permanecer nas mãos dos órgãos oficiais.

Uma segunda tentativa de implantar no Brasil o programa escolar evangélico coube ao SIL através de Townsend, em uma reunião do III em 1954. A oferta de Townsend foi recusada. O diretor do SPI e chefe da delegação, José Maria da Gama Malcher, justificou a recusa pelo fato de serem eles missionários (Hefley \& Hefley, 1974, p. 174). A proposta do SIL de trabalhar na área de educação indígena tinha sido considerada inconstitucional porque transferia para estrangeiros as tarefas do Estado como tutor dos índios (Oliveira, 1981).

A restrição ao SIL no Brasil surgia por parte dos indigenistas, que até então haviam sido, na América Latina, aliados tradicionais da missão. A negativa à oferta do SIL pode ser explicada pelo indigenismo influenciado por Marechal Cândido Rondon. A inspiração de Rondon não era a antropologia, como no México, mas Augusto Comte (Ribeiro, 1986, p. 134-5). Nesse modelo de indigenismo positivista, não havia um lugar vacante de lingüista a ser preenchido.

Somente em 1972, o SIL conseguiu oficializar o programa de educação necessário ao tradutor bíblico por meio da introdução da lingüística como base teórica da escola indígena. O lingüista (do SIL) era a figura 
Maria C. D. M. Barros. A missão Summer Institute of Linguistics...

principal dessa escola indígena, e não mais o pedagogo ou o antropólogo, como no padrão das escolas do SPI (1954). Pela portaria da Funai de 1972, a regra a ser seguida na criação dos alfabetos para as escolas seria: "para cada fonema, um único símbolo" (Funai, Portaria n. 75, 6/7/1972). A oficialização do programa de educação do SIL no Brasil aconteceu em um contexto relacionado ao III: ocorreu um mês antes da reunião do Instituto Indigenista Interamericano em Brasília, onde os membros do SIL participaram como observadores de várias delegaçóes (México, Brasil, Bolívia, Colômbia, Equador e Suriname). Naquela mesma reunião, Tonwsend ganhava do III o prêmio de "Benfeitor das populações lingüisticamente isoladas das Américas” (SIL, 1986).

\subsubsection{Relaçôes contratuais com os governos: os "convênios"}

$\mathrm{Na}$ entrada do SIL no Peru houve uma novidade em relação ao México que foi fazê-lo por meio de convênios com o governo, o que depois se tornou o padrão da entrada da missão. No México, apesar das boas relações que manteve com o governo mexicano, o SIL não tinha relações formais até aquela época; sua permanência no país se baseava principalmente no compadrio político como forma de sustentação da missão. $\mathrm{O}$ primeiro convênio no México foi assinado apenas em 1951, posterior à entrada da missão no Peru.

O convênio do SIL com o governo peruano em 1945 permitia facilidades na legalização da documentação do pessoal da missão, na isenção para importação de material, na concessão de espaços em escritórios do governo para o seu pessoal e na terra para construir uma base e licença para avióes e pilotos (Hefley \& Hefley, 1974).

O convênio tinha o perfil de uma concordata modernizada. Pelos termos do convênio com o governo peruano, a área de atuação da mis- 
Revista de Antropologia, São Paulo, USP, 2004, v. 47 no 1.

são era a Amazônia. A escolha dessa região foi de interesse mútuo do governo e da missão. Para o governo peruano, era conveniente que a missão se estabelecesse na Amazônia pelo papel que ela exerceria a favor da integração da região à economia nacional. Para Townsend, a Amazônia representava um lugar mitológico para o missionário com ambições de pioneiro e desbravador das fronteiras do mundo não-evangélico. Um outro motivo estava ligado à possibilidade futura de expandir a missão: as atividades educacionais no Peru poderiam funcionar como um cartão de entrada da missão nos países que fossem contíguos à Amazônia (Hefley \& Hefley, 1974).

No Brasil, ao contrário do resto da América Latina, a missão não entrou por convênio com a burocracia indigenista e sim com a academia. Depois da negativa de entrar por meio do SPI em 1954, a missão fez em 1956 contatos com o Museu Nacional com a oferta de pesquisar línguas indígenas pela metodologia lingüística. $\mathrm{O}$ emissário da missão foi Kenneth Pike, que apresentava um perfil acadêmico (grau de doutor, professor universitário etc.). Dessa vez, houve aceitação, tendo o SIL conquistado seu primeiro acordo para entrar no país. No Museu Nacional foi criado o Setor de Lingüística para abrigar os missionários. O prestígio da lingüística americanista entre setores intelectuais foi a forma de sustentação inicial da missão no país. Seus membros foram identificados como "discípulos" da Escola de Boas (Câmara, 1977, p. 65).

Nesse período, a permissão para entrar em área indígena era feita por intermédio do Museu Nacional. A academia era importante, pois era o lugar onde se reforçava a imagem de lingüista, mas o exercício pleno da estratégia de evangelização só ocorreria por meio de convênio com o órgão que tivesse a seu cargo a educação indígena. A mudança da sede do SIL do Rio para Brasília no início da década de 1960 indica uma maior atenção da missão para o órgão indigenista do que para a academia, com quem o SIL mantinha o convênio. 
Maria C. D. M. Barros. A missão Summer Institute of Linguistics...

Para negociar um convênio com o SPI, o SIL teve em 1961 uma audiência com o presidente da República, como já havia feito em outros países. Townsend menciona que a visita a Jânio Quadros foi intermediada por Velasco Ibarras, então presidente do Equador. Para falar com o presidente, não foi enviado o lingüista Pike, mas o estadista da missão, William C. Townsend. Como brinde tradicional dos missionários lingüistas, Townsend levou materiais escritos em línguas ágrafas: cartilhas e trabalhos lingüísticos (Hefley \& Hefley, 1974, p. 201), em especial sobre os Terena, grupo indígena do estado natal do presidente. Junto com os presentes foram alguns pedidos: a assinatura de convênios com o Serviço de Proteção aos Índios e com a futura Universidade de Brasília, além da autorização para operar com rádios e aviōes no Brasil. James Wilson, do SIL no Brasil, informava na Conferência Bienal da Missão que o presidente havia se mostrado favorável aos pedidos de Townsend e que se estava negociando os termos do convênio (Wilson, 1961, p. 38). A renúncia de Quadros não deu chance de conquistar o primeiro convênio com o órgão indigenista.

O novo governo, mais próximo de Darcy Ribeiro, representou uma boa conjuntura para a missão no país. As metáforas tradicionais dos missionários para identificar uma boa relação com o governo - "paredes que caem", "portas que se abrem" - foram usadas para caracterizar 1962 como um ano profícuo para o SIL (Wilson, 1964, p. 51). As boas relações oficiosas da missão com o Estado permitiram que o SIL crescesse de 74 para 104 membros (Wilson, 1964, p. 50). Muitas facilidades foram dadas pela nova direção do SPI: ampliação das autorizações de entrada para novos membros (ainda por meio do Museu Nacional), apoio junto a outros órgãos públicos para conseguir autorização para aviões e rádios e permissão para construir casas nos postos indígenas, ponto que não estava contemplado no convênio com o Museu. O golpe militar de 
1964 obrigou os missionários a procurarem novos aliados; seu "protetor" Ribeiro era agora um exilado, não podendo, por isso, ser uma fonte de apoio.

Apenas em 1969, o SIL assinou seu primeiro convênio com o governo. $\mathrm{O}$ indigenismo do período dos governos militares foi o que permitiu o convênio entre uma missão religiosa e o órgão indigenista. A assinatura do convênio foi possível depois que o SPI foi extinto em 1967 e substituído pela Fundação Nacional do Índio (Funai). Indícios de uma boa relação entre governo e missão nesse período foi a premiação, em 1967, de Townsend com a condecoração da Ordem do Cruzeiro do Sul (WBT/SIL, 1971). O SIL deu maior relevo ao convênio com o Ministério do Interior e Funai do que aos assinados com a academia.

At first our contract was with the National Museum in Rio, part of the University of Brazil. Since then our position has been strengthened by a further contract with the University of Brasilia, and greatest of all, a contract with the ministry of the Interior. (Wycliffe Bible Tranlators in Brazil, 1969)

O SIL levou 12 anos para assinar seu primeiro convênio com o indigenismo no Brasil. Um fator que explica a dificuldade da missão de atuar junto ao SPI e sua entrada por um órgão acadêmico é a tradição do indigenismo de Cândido Rondon. Em geral, os convênios assinados com o governo brasileiro foram os mais curtos (de dois a quatro anos), se forem comparados com os do Peru (dez anos foi o tempo médio dos convênios). 
Maria C. D. M. Barros. A missão Summer Institute of Linguistics...

\subsection{Fim das alianças: a dupla identidade como "conspiração"}

A partir dos anos 1970, o jogo da dupla identidade do SIL (missionário oculto versus publicidade à identidade de lingüista) foi associado a uma política conspiratória, na qual os membros do SIL foram tomados como agentes da CIA ou geólogos em busca de minerais (Stoll, 1985).

Um dos primeiros focos de críticas ao SIL surgiu em um contexto acadêmico, o Congresso Americanista de 1970 reunido em Lima. Em 1971, as críticas ganharam o espaço de uma reunião organizada pela Comissão Mundial de Igrejas em Barbados. Houve também críticas nos fóruns latino-americanos, inclusive no de seu antigo aliado, o III: o prêmio recebido por Townsend em 1972 foi retirado durante a reunião do órgão no México em 1979, e se incluía nas resoluções finais a necessidade de investigar as ações da missão no continente (Stoll, 1985).

Tem início o período de crises nas relações da missão em toda a América Latina. A crítica à missão ganhou os fóruns acadêmicos e também os governos. Vários países (Panamá, Equador, Brasil, Peru, Colômbia e México) não renovaram os contratos com o SIL, ainda que por um curto período. A missão já não congregava em torno de si um consenso favorável, como tinha sido desde a década de 1930.

Stoll (1984) levanta algumas razões para a passagem do SIL de aliado a inimigo: o declínio da atuação das missões católicas em áreas indígenas, depois do movimento da Teologia da Libertação; surgimento dos movimentos indígenas, com a reivindicação de agentes da política indigenista em detrimento do papel gerencial que tinham os órgãos indigenistas. Também, no plano intelectual, já não havia vacância do papel de lingüista nas universidades desses países, com o surgimento de vários programas de pós-graduação nessa disciplina.

O fim da política de aliança com a parcela não-evangélica, como forma de sustentação política, pode ser vista nos últimos anos na forma 
de atuação do SIL no Brasil, onde a missão tem se articulado com outros grupos evangélicos. A missão faz parte hoje, junto a outras missões evangélicas, da Associação de Missões Transculturais Brasileiras e do Conselho das Missões Evangélicas (Arquivo da Funai/Brasília). A criação, no Brasil, da Associação Lingüística Evangélica Missionária (Alem), à imagem e semelhança do SIL, com evangélicos brasileiros, aponta uma mudança de estratégia política, baseada agora nos aliados nacionais evangélicos.

\section{Conclusão:}

\section{uma missão moldada ao indigenismo latino-americano}

Em sua expansão pelo mundo, o SIL fez uso de apoio de grupos da direita e da esquerda. No Vietnã, nas Filipinas e na Indonésia, teve apoio do governo americano. Para entrar na União Soviética, Townsend fez uso do México como canal diplomático, em particular de Cardenas (Stoll, 1985, p. 241).

Dessa gama de apoios que a missão manteve entre grupos politicamente diferenciados, o presente trabalho se restringiu à aliança do SIL com grupos nacionais não-evangélicos, em particular os indigenistas. Entre as décadas de 1930 e 1970, a estratégia da missão SIL na América Latina foi priorizar no "campo" (field) as relaçóes com o governo e a academia, antes de estabelecer relações com grupos evangélicos nesses países (Cowan, 1979, p. 214). Essa estratégia de aproximação foi dirigida privilegiadamente aos órgãos indigenistas estatais, recém-estabelecidos na América Latina, tendo a missão sido projetada em sua criação para atuar conforme as regras do indigenismo estatal de definição anticlerical. A entrada e a expansão do SIL no continente estiveram asseguradas na medida em que sua prática havia se moldado às exigências do indige- 
Maria C. D. M. Barros. A missão Summer Institute of Linguistics...

nismo estatal (cientificidade e laicismo) por meio do jogo da dupla identidade, no qual se mantinha oculta a identidade de missionário e se enfatizava a identidade de lingüista, agregando depois do nome da missão o da Universidade de Oklahoma.

Nessa estratégia das alianças na América Latina, o SIL/WBT se constituiu como uma missão com dois públicos e, para cada público, uma identidade: missionário pioneiro para o público de "casa" e lingüista para o público do "campo". Essa foi a forma de harmonizar dois grupos de apoio da missão ideologicamente contraditórios.

A missão moldou seu desenho institucional ao sabor das conjunturas políticas enfrentadas com seus dois públicos. Townsend redesenhou os contornos institucionais da missão de maneira a poder levar à frente suas alianças tão diferenciadas. Uma das últimas transformações institucionais da missão, para responder ao contexto político no campo, é a mudança de nome da missão no Brasil para Sociedade Internacional de Lingüística, nome usado nos países de língua francesa (James Wilson, comunicação verbal). Dessa maneira, conserva-se a sigla SIL, mas deixa de ser Summer Institute of Linguistics. Procura-se um novo nome para se separar do passado da missão.

O jogo da dupla identidade foi profícuo para a história da missão na América Latina, possibilitando-lhe de ter ingerência na educação indígena pública para dirigi-la às exigências do modelo evangélico do tradutor bíblico. O SIL se tornou sócio na formulação do projeto educacional para o indigenismo estatal.

Por fim, a história da relação dos missionários fundamentalistas com os indigenistas de base antropológica pode ser pensada de uma forma similar à que Ribeiro visualiza no romance Maíra, como a relação entre os índios e os indigenistas do Serviço de Proteção ao Índio. Para Ribeiro, entre esses dois havia um "jogo de interesses recíprocos, quem sabe inconscientes, entre protegidos e protetores. Jogo no qual estes últimos 
são os verdadeiros beneficiários" (Ribeiro, 1976, p. 352). Essa caracterização pode ser estendida para a relação estabelecida entre os missionários do Summer Institute of Linguistics e os órgãos indigenistas na América Latina: entre eles se estabeleceu um jogo de interesses recíprocos, dos quais o beneficiário foi a missão.

\section{Bibliografia}

ASAMBLEA DE FILOLOGOS Y LINGUISTAS

1940 Memoria, 1, México, Departamento Autonomo de Asuntos Indígenas.

BASAURI, C.

1937

"La Psicologia a través del estudio de las lenguas y su importancia para la educación indígena”, Investigaciones Linguisticas, t. 4, n. 1/2, México.

BREND, R. \& PIKE, K. (Ed.)

1977

The Summer Institute of Linguistics. Its works and contribution, Mouton, The Hague.

CÂMARA, J. M.

"Comentário do co-relator J. Mattoso Câmara Jr. ao relatório do professor Aryon Rodrigues. 1963-1965”, in SCHADEN, E. (ed. ), Homem, cultura e sociedade no Brasil. Seleçôes da Revista de Antropologia, 2. ed., Vozes (Estudos Brasileiros I).

CARDENAS, L.

1973 Obras, México, Unam, Dirección General de Publicaciones.

COLBY, G. \& DENNET, C.

1995

Seja feita a vossa vontade. A conquista da Amazônia: Nelson Rockefeller e o evangelismo na idade do petróleo, Rio de Janeiro, Record.

COWAN, G. M.

1979

The Word that Kindles, New York, Christian Herald Books, 272 pp. 
Maria C. D. M. Barros. A missão Summer Institute of Linguistics...

DANIELS, J.

1947

Shirt-Slave Diplomat, Chapel Hill, The University of North Carolina.

DYE, T. W.

1979

The Bible translation strategy: an analysis of its spiritual impact, Papua New Guinea, SIL, 257 pp.

FERNANDES, R. C.

1980 Um exército de anjos - as razões da missão Novas Tribos, Religiāo e Sociedade, n. 6 , p. $129-65$.

FREIRE, C. A. da R.

1990

Indigenismo e Antropologia. O Conselho Nacional de Proteção aos Índios na gestão Rondon (1939-1955), Rio de Janeiro, dissertação, Museu Nacional.

FUNAI

1972

Normas para educação dos grupos indigenas. Portaria n. 75/N, de 6/7/1972, mimeografado anexo ao material do curso de Lingüística do SIL, 1976.

GAMIO, M.

1960

Forjando patria, 2. ed., México, Porrua.

HEFLEY, J. C.

1982

God's Free-Lancers, 2. ed., Orange, California, Wycliffe Associates.

HEFLEY, J. \& HEFLEY, M.

$1974 \quad$ Uncle Cam. The story of William Cameron Townsend, founder of the Wycliffe Bible Translator and the Summer Institute of Linguistics, Waco, Word Books.

INSTITUTO INDIGENISTA PERUANO

1948 a 1953 Peru Indigena, Lima.

INSTITUTO MEXICANO DE INVESTIGACIONES LINGUÍSTICAS

1933 a 1938 Investigaciones Lingüisticas, México. 
LARSON, M. L. \& DAVIS, P. M. (Ed.).

1981

Education: an experience in Peruvian Amazonia, Dallas/Washington, Summer Institute of Linguistics/Center for Applied Linguistics, 417 pp.

LATHROP, M.

1937

"Report of a partial study of the Tarascan Dialect", Investigaciones Linguisticas, t. IV, n. 1/2, p. 111-29.

1940 "Tarasco", Pioneer Mission News, May, p. 11.

LEGTERS, L. L.

"Report of Mr. L. L. Legters, Field Secretary, Sep. 18”, Pioneer News, Dec.

McQUOWN, N. A.

1939

"Información general acerca de la labor del Consejo de Lenguas Indigenas de Mexico", Boletin Bibliografico de Antropologia Americana, vol. III, Sep.-Dec., n. 3, p. 221-2.

NIDA, E.

Bible Translating, an analysis of principles and procedures with special reference to aboriginal languages, New York, American Bible Society, 359 pp.

OLIVEIRA, R. C.

"Deve o Summer permanecer no Brasil?", Religiāo e Sociedade, n. 7, Rio de Janeiro, p. 66-7.

PIKE, E.

1981

Ken Pike, scholar and christian, Dallas, SIL, 268 pp.

RIBEIRO, D.

1954

"O Serviço de Proteção aos Índios e as missōes religiosas", Relatório das atividades do Serviço de Proteção aos Índios durante 1954.

1976

Maira, Rio de Janeiro, Civilização Brasileira, 408 pp.

1986

Os indios e a civilização. A integração das populações indígenas no Brasil moderno, 5. ed., Petrópolis, Vozes.

SÁENZ, M.

1936

Carapan, bosquejo de una experiencia, Lima, Libreria e Imprenta Gil. 
Maria C. D. M. Barros. A missão Summer Institute of Linguistics...

\section{SERVIÇO DE PROTEÇÃO AOS ÍNDIOS}

1954 Relatório das atividades do Serviço de Proteção aos Indios, datilografado.

\section{SUMMER INSTITUTE OF LINGUISTICS}

1986 1981-1983, Brasília.

STEVEN, H. \& HEFLEY, J. C.

1972 Miracles in Mexico, Chicago, Moody Press, 126 pp.

STOLL, D.

1981 "Words can be used in so many ways", in SOREN, H. \& PETER, A. Is God an American? An anthropological perspective on the missionary work of the Summer Institute of Linguistics, Survival International/ IWGLIA.

1984

"Con que derecho adoctrinam ustedes a nuestros indigenas?: la polemica en torno al Instituto Linguistico de Verano", América Indígena, vol. XLIV, eneromarzo, p. 9-24.

1985

Pescadores de Hombres o Fundadores de Imperio?, Lima, Desco/Centro de Estudios y Promoción del Desarrollo, 489 pp.

SWADESH, M.

"Proyecto de Plan de educación indigena en lengua nativa tarasca", Boletin Bibliografico de Antropologia Americana, vol. III, sep.-dic., n. 3, p. 222-7.

SWADESH, M.

"La capacidad expresiva de las lenguas nativas", Primer Congreso Indigenista Interamericano, p. 290-308, mecanografado.

TOWNSEND, G. C.

1936 "Tolo, the volcano's son. A tale of Indian and upheaveal in Central America", Revelation, Apr.-Oct. (2. ed., 1981, Wycliffe Bible Translators, California.)

1944 "El Instituto Linguistico de Verano", Boletin Indigenista, vol. IV, mar., n. 1, p. 46-52, Instituto Indigenista Interamericano.

1949 "El aspecto romantico de la investigación lingüística", Peru Indigena, n. 2, Instituto Indigenista Peruano. 
Revista de Antropologia, São Paulo, USP, 2004, v. 47 no 1.

TOWNSEND, W. C.

1952 Lazaro Cardenas, Mexican democrat, Michigan, George Wahr Publishing Co.

WALLIS, E. E. \& BENNETT, M. A.

1959 Two thousand tongues to go. The story of the Wycliffe Bible Translators, New York, Harper and Brothers Publisher.

WILSON, J. W. (Acting Director)

1961 "Report of the Brazil Branch of WBT/SIL", in Reports Biennal Conference of WBT/SIL, p. 36-40, Sulphur Springs, Arkansas/Santa Ana (California).

WILSON, J.

1964 "Report of the Brazil Branch of WBT/SIL", in Report, p. 50-5.

WYCLIFFE BIBLE TRANSLATORS IN BRAZIL

1969 Difusão Européia do Livro.

WBT/SIL

1971 Biennal reports, Mexico.

YANNAKAKIS, Y.

1997 "Civilization", "Barbarism" and Culture: Presbyterian Missionary Ideology and Practice in the Guatemalan Highlands, 1882-1960, University of Pennsylvania, manuscrito. 68 pp.

ABSTRACT: This work outlines the history of the alliance between the Evangelical Mission Summer Institute of Linguistics and Latin American scholars between the 1930s and 1970s, aiming to reconstruct the political and intellectual context of this alliance in Mexico, Peru and Brazil. Particular focus will be drawn to the role that the Interamerican Indigenist Institute played in providing links between the Mission and Latin American governments.

KEY WORDS: Evangelical missions, Summer Institute of Linguistics, Indigenism, Interamerican Indigenist Institute, Indigenous Linguistics.

Aprovado em abril de 2004. 